\title{
EKSISTENSI GURU KELAS MI DALAM MENGEMBANGKAN KOMPETENSI INTI PESERTA DIDIK
}

\author{
Resti Septikasari ${ }^{1}$, Yayuk Hidayati ${ }^{2}$ \\ ${ }^{1}$ STKIP Nurul Huda Sukaraja \\ ${ }^{2}$ SDN 01 Sri Menanti \\ ${ }^{1}$ Karang Jadi, Belitang III, ${ }^{2}$ Nusa Tunggal, Belitang III \\ restisari04@stkipnurulhuda.ac.id, hidayatiyayuk638@gmail.com
}

\begin{abstract}
The purpose of this study was to find a hypothesis on the causes of the development of the students' core competencies. The method used is qualitative with a sample of data sources totaling 6 teachers. Data collection techniques using observation, interviews and documents.Technical analysis of data using the analysis of Miles and Hubermanmodel. The results of this study are 1) Being a role model. During the teaching and learning process, the teacher not only commands students to do good things, but also has to give an example first. 2) Give attention. In giving attention, teachers should not differentiate between students who have strengths and weaknesses, 3) Good communication. This communication aims to train students to deepen knowledge about attitudes towards something, or how to respond to something properly and correctly, 4) Inviting to visit the houses of residents affected by the disaster, 5) Supervising the teachers and parents so that all activities learners can be seen.
\end{abstract}

Keywords: Existence, classroom teacher, Core Competencies

\begin{abstract}
Abstrak:Tujuan penelitian ini adalah menemukan hipotesis dari penyebab berkembangnya kompetensi Inti peserta didik. Metode yang digunakan yaitu kualitatif dengan sampel sumber data yang berjumlah 6 guru.Teknik pengumpulan data menggunakan observasi, wawancara dan dokumen. Teknis analisis data dengan menggunakan analisis model Miles and Huberman. Hasil penelitian ini adalah 1) Menjadi teladan.Ketika proses belajar mengajar, guru tidak hanya memerintah peserta didik untuk melakukan hal yang baik, namun juga harus mencontohkan terlebih dahulu. 2) Memberikan perhatian. Dalam memberikan perhatian, guru tidak boleh membedakan antara peserta didik yang memiliki kelebihan dan kekurangan, 3) Komunikasi dengan baik.Komunikasi tersebut bertujuan melatih peserta didik untuk mendalami pengetahuan bagaimana sikap terhadap sesuatu, atau bagaimana menyikapi suatu hal denganm baik dan benar, 4)Mengajak berkunjung ke rumah warga yang terkena musibah, 5) Melakukan pengawasan yang dilakukan oleh guru dan orang tua agar segala aktivitas peserta didik dapat dilihat.
\end{abstract}

Kata Kunci: Eksistensi, Guru kelas, Kompetensi Inti

Dendidikanakan berhasil apabila tujuan
yang dirumuskan dapat tercapai.

Setiap satuan pendidikan pasti memiliki tujuan yang ingin dicapai. Untuk 56| J P D, p - I S S N : 2252-8156, e - IS S N : 2579-3993 merumuskan tujuan dalam satuan pendidikan itu harus menyesuaikan dengan tujuan pendidikan nasional. Jika tidak, tentunya akan menyimpang dari apa yang 
dikehendaki oleh Negara. Tujuan pendidikan Nasional itu sendiri yaitu berkembangnya potensi peserta didik agar menjadi manusia yang beiman dan bertaqwa kepada Tuhan Yang Maha Esa, berakhlak mulia, sehat, berilmu, cakap, kreatif, mandiri dan menjadi warga Negara yang demokratis serta bertanggung jawab. Dari tujuan tersebut sangatlah penting bagi satuan pendidikan untuk menyiapkan Segala sesuatunya.Dalam mencapai tujuan tersebut menteri pendidikan mengemas kurikulum dengan sebaik mungkin.

Kurikulum adalah konsep yang berisi rencana dan pengaturan mengenai tujuan, isi dan bahan pelajaran yang digunakan sebagai pedoman penyelenggaraan pembelajaran untuk mencapai tujuan.(Fauzan, 2017)Pada tahun 2013 pemerintah telah mengimplementasikan kurikulum 2013. Implementasi kurikulum ini masih dilakukan secara bertahap.(Fery \& Saputro, 2019)Tentunya kurikulum 2013 ini dibentuk menyesuaikan dengan tujuan pendidikan nasional atau menyesuaikan dengan apa yang diinginkan oleh Negara Indonesia terkait pendidikan. Tujuan pendidikan nasional berfokus pada karakter peserta didik. Untuk mencapai tujuan tersebut, maka dibutuhkan profil kualifikasi kemampuan lulusan yang kemudian dituangkan ke dalam Standar Kompetensi Lulusan (SKL). Standar 57 | J P D , P - I S S N : $2252-8156$ kompetensi lulusan adalah kualifikasi kemampuan lulusan yang mencakup sikap, pengetahuan dan keterampilan yang harus dipenuhi oleh peserta didik.(Triyanto, 2017)Dalam implementasinya, untuk mencapai SKL tersebut dibentuklah kompetensi inti yang mana setiap mata pelajaran harus diintegrasikan dengan kompetensi inti. Kompetensi inti adalah pengikat berbagai kompetensi dasar yang harus dihasilkan dengan mempelajari tiap mata pelajaran serta berfungsi sebagai integrator horizontal antar mata pelajaran.(Triyanto, 2017)Artinya dalam setiap mata pelajaran harus mengaitkannnya dengan pembentukan sikap, pengetahuan dan keterampilan. Kompetensi inti diibaratkan seperti anak tangga yang harus dilalui oleh peserta didik. Kompetensi inti meningkat seiring dengan meningkatnya usia peserta didik yang dinyatakan dengan naik kelas.

Kompetensi inti mencakup bebrapa aspek, diantaranya sikap spiritual, sikap social, pengetahuan dan keterampilan yang berfungsi sebagai pengintegrasi muatan pembelajaran dan mata pelajaran.(Asmarawati et al., 2016)

Permasalahan yang terjadi adalah tidak semua guru dapat mengelola sikap spiritual dalam pembelajaran. Padahal sudah jelas disebutkan dalam pembelajaran kurikulum 2013 harus mengintegrasikan I S S N : 2579 - 3993 
dengan mata pelajaran.(Ihwana et al., 2017)

Tidak sedikit dalam berita di tanah air seorang anak menganiaya gurunya, membunuh anak kecil, menganiaya teman sebayanya dan lain sebagainya. Hal ini perlu diperhatikan baik oleh orang tua maupun guru di sekolah. Untuk mengurangi hal ini setidaknya ada upaya pencegahannya yaitu dengan menanamkan sikap yang baik kepada anak baik di rumah maupun di sekolahan. Pihak sekolah juga harus menjalin hubungan dengan wali murid untuk mengawasi dan memperhatikan sikap ketika di luar sekolah baik dalam mengerjakan pekerjaan rumah maupun pekerjaan dari sekolah.

Orang tua perlu mengawasi kegiatan belajar peserta didik.Hal ini dilakukan untuk mengevaluasi apakah anak telah mempunyai kebisaaan tentang sesuatu yang ditanamkannya atau diajarkannya, apakah untuk menguatkan itu perlu ganjaran dan hukuman.Pengawasan disini juga berguna untuk menghindarkan anak dari bahaya bahaya yang merugikan perkembangan baik jasmani maupun rohaninya.

Hubungan yang terjalin harmonis dan perhatian yang penuh kasih sayang dari orang tua akan memberikan rasa nyaman bagi peserta didik dalam belajar.(Mawarsih et al., 2013)Adanya interaksi guru dengan peserta didik saat proses pembelajaran ditunjukkan dengan cara guru memberikan pemodelan, arahan, motivasi, teguran, peringatan, penugasan dan penguatan. Guru menggunakan bahasa yang mudah dipahami dan halus.(Suandi, 2014)Keluarga mempunyai peranan penting dalam memberikan pendidikan dan dan perlindungan terhadap anak. Pengenalan anak kpeda pendidikan, kebudayaan dan norma semuanya berawal dari lingkungan keluarga. Oleh karena ini pendidikan sangat penting dalam keluarga.(Nisa Program Studi Bimbingan Konseling, 2015)

Sementara, guru menjadi focus utama untuk mewujudkan keberhasilan pendidikan sesuai dengan tujuan pendidikan nasional. Guru sebagai panutan peserta didik dan masyarakat, sebagai prosedur yang membuat dan menyusun scenario pembelajaran, karena guru sebagai pemegang estapet terakhir dalam pendidikan untuk menjadikan peserta didiknya menjadi berintelektual dan berkarakter.(Busyaeri \& Muharom, 2016)

Peserta didik di MI Muhammadiyah telah menunjukkan keberhasilan dalam mencapai kompetensi inti terutama sikap spiritual dan sikap social. Hal ini ditandai adanya banyak peserta didik yang menjaga sikapnya baik ketika dalam beribadah maupun berinteraksi dengan masayarakat. 58| J P D, p - I S S N : 2252-8156, e - I S S N : $2579-3993$ 
Kepala Madrasah telah memberikan kebijakan terutama untuk Guru kelas agar menjalankan tugasnya sesuai dengan kebijakan yang sudah dibuat. Peserta didik selalu ditanamkan nilai-nilai seperti yang sudah dituang dalam kompetensi inti, agar nantinya kompetensi lulusannya tercapai sehingga tujuan Pendidikan Nasional bisa terwujud. Guru mengupayakan memberikan ilmu yang bermanfaat bagi peserta didik dan juga masyarakat banyak.

Kedudukan sikap spiritual dalam kurikulum 2013 sangat penting sekali karena hal ini merupakan kompetensi yang pertama dari yang lainnya, serta pembelajarannya harus setus disampaikan dan dijadikan pembiasaan.(Wiguna, 2017)

Sebagai seorang guru professional tugas utamanya adalah mendidik, mengajar, membimbing, mengarahkan, memberi teladan, melatih dan mengevaluasi serta dituntut untuk dapat merencanakan, memahami peserta didik, memahami pemilihan metode, strategi.(Fauzan, 2017)

Penelitian ini bertujuan untuk menemukan hipotesis karena dalam lapangan terdapat kasus yang positif yang peneliti ingin menelusuri lebih dalam tentang penyebab keberhasilan guru dalam mengembangkan kompetensi inti peserta didik di MI Muhammadiyah Senumarga. Kompetensi Inti Peserta Didik.Harapan 59| J P D , p - I S S N : 2252 - 8156 peneliti adalah agar sekolah/madrasah sekitarnya dapat menjadi wawasan baru untuk megembangkan kompetensi inti peserta didik.

\section{METODE PENELITIAN}

Metode yang digunakan adalah kualitatif.Sumber data penelitian sebanyak 6 guru kelas MI Muhammadiyah Senumarga.

\section{Teknik pengumpulan data}

Teknik pengumpulan data menggunakan observasi, wawancara dan dokumen.

Melalui observasi, peneliti belajar mengenai perilaku dan makna dari perilaku tersebut.Observasi yang digunakan dalam penelitian ini adalah observasi tidak terstruktur, karena focus permasalahan dalam penelitian ini belum jelas. Observasi tidak terstruktur adalah observasi yang tidak dipersiapkan secara sistematis tentang apa yang diobservasi.(Sugiyono, 2020)

Teknik wawancara yang digunakan dalam penelitian ini adalah wawancara tidak berstruktur.Wawancara tidak berstruktur adalah wawancara yang bebas dimana peneliti tidak menggunakan pedoman wawancara dalam pengumpulan data.Alat wawancara yang digunakan adalah buku catatan, perekam suara (menggunakan HP) dan camera (HP).

Dokumen merupakan catatan peristiwa yang sudah berlalu. Dokumen I S S N : 2579 - 3993 
yang digunakan penelitian ini adalah dokumen yang terkait dengan kurikulum madrasah, guru dan peserta didik di MI Muhammadiyah Senumarga

\section{Teknik Analisis Data}

Teknik analisis data dalam penelitian ini adalah menggunakan model Miles dan Huberman. Aktivitas dalam menganalisis data kualitattif dilakukan secara interaktif dan berlangsung secara terus menerus sampai tuntas, sehingga datanya sudah jenuh. Aktivitas dalam analisis data yaitu data reduction, data display dan juga data conclusion drawing/verification

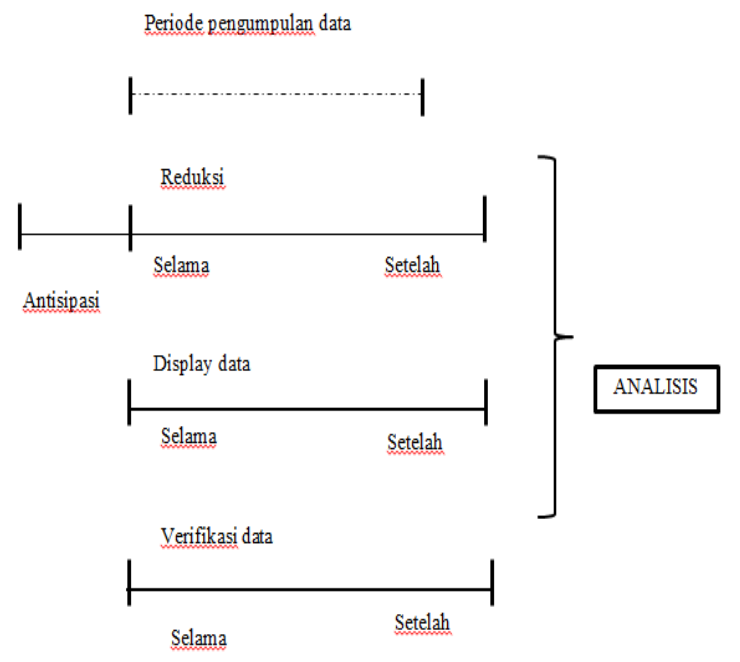

\section{HASIL DAN PEMBAHASAN}

Pada bagian ini dipaparkan temuan penelitian di lapangan yang diambil di MI Muhammadiyah Senumarga.Ada 6 guru kelas di MI Muhammadiyah Senumarga yang menjawab pertanyaan dari peneliti.Dari berbagai jawaban dari informan, selalu ada pertanyaan baru yang menarik dan unik untuk dibahas. Oleh sebab itu penelitian ini sudah beberapa kali mengalami perubahan judul tetapi masih dalam satu tema yang sama. Dari keenam guru tersebut menjelaskan semua keeksistensinya dalam mengembangkan sikap spiritual dan social. Guru menjelaskan perlunya dilakukan pembisaaan dalam beribadah. MI Muhammadiyah Senumarga melakukan shalat dhuha bersama dan menghafalkan surat surat pendek beserta artinya dan dilanjutkan dengan siraman rohani dengan menceritakan kisah Nabi dan sahabat. Tentunya hal ini diupayakan dapat mendorong peserta didik untuk taat kepada Allah SWT dan meneladani sikap Nabi Muhammad SAW beserta sahabatsahabatnya. Dalam proses pembelajaran, sebelum pulang, peserta didik juga dibekali dengan cerita yang mengandung pesan di dalamnya. Cerita tersebut merupakan cerita yang sering terjadi dalam kehidupan sehari-hari.Harapannya agar peserta didik dapat menceritakannya kembali kepada orang tua di rumah. Dengan begitu peserta didik akan menjelaskan pesan yang terkandung dalam cerita tersebut ketika kembali ke sekolahan.

Kurikulum 2013 yang saat ini sedang berlangsung dilakukan pada setiap jenjang satuan pendidikan memang merupakan bukan hal yang baru, namun dalam mengimplementasikannya harus sesuai 60| J P D, p-IS S N : 22 252-8156, e - I S S N : 2579-3993 
dengan tujuannya. Mengenai hal ini, guru kelas di MI Muhammadiyah Senumarga menjelaskan bahwa untuk mengghasilkan output yang baik tentunya out comenya juga harus baik. Ada beberapa hal yang dilakukan guru agar peserta didik memiliki sikap yang baik yaitu:

1. Menjadi teladan

Ketika proses belajar mengajar, guru tidak hanya memerintah peserta didik untuk melakukan hal yang baik, namun juga harus mencontohkan terlebih dahulu. Misalnya guru selalu membaca bismillah ketiaka setiap akan melakukan aktivitas. Dan bacaan itu diupayakan didengar oleh peserta didik. Jika semua guru menarpkan hal ini, maka peserta didik akan dengan mudah membisaakan hal ini. Ketika di dalam kelas, saat bersin, guru juga membisaakan untuk menjawab seperti Islam mengajarkan.Hal ini sering kali dilalaikan oleh berbagai kalangan.Ketika peserta didik mendspstksn nilai yang bagus untuk selalu membisaakan mengucap Alhamdulillah sebagai rasa syukur kepada Allah SWT.Guru juga sering membisaakan mengucapkan terimakasih ketika ada peserta didik yang mengambilkan barang guru yang sengaja dijatuhkan supaya diambil oleh pserta didik lalu mengucapkan terimaksih.

2. Memberikan perhatian

Perhatian memang sangat perlu dilakukan oleh guru dan juga orang tua peserta didik agar mudah untuk diingat dan dilakukan.Di sekolahan guru juga memberikan perhatian penuh kepada semua peserta didik.Tidak hanya memberikan perhatian kepada yang pintar, baik, kaya dan anak pejabat saja tetapi kepada anak yang kurang mampu, kurang perhatian, dan anak yang dalam keluarganya mengalami broken home yang hidupnya tidak ada yang mempehatikan.Semua anak memiliki hak untuk diperhatikan walaupun dalam hal yang kecil sekalipun. Dari masalah pakaian, sikap, kemampuan dan lain lain harus diperhatikan oleh guru. Ketika ada anak yang sifatnya beda dari teman temannya yang lain, seorang guru tidak boleh membandingkan dengan peserta didik lainnya. Karena jelas kemampuaan setiap anak itu berbeda beda. Peserta didik yang memiliki sikap tempramen tidak selayaknya untuk dikasari juga. Peserta didik akan luluh jika guru terus menerus melakukan perhatian kepada peserta didik.

3. Komunikasi yang baik

61| J P D, p - I S S N : 2252-8156, e - I S S N : 2579-3993 
Mengajak komunikasi peserta didik dapat membangkitkan semangat peserta didik dalam melakukan kegiatan.Komunikasi tersebut bertujuan melatih peserta didik untuk mendalami pengetahuan tentang bagaimana sikap terhadap sesuatu, atau bagaimana menyikapi suatu hal denganm baik dan benar. Tanpa berkomunikasi dengan peserta didik, guru akan sulit memasuki dunia peserta didik yang sebenarnya. Seperti yang telah diketahui bahwa komunikasi yang baik akan menghasilkan pemahaman terhadap lawan berbicara. Komunikasi yang baik dalam hal ini berkaitan juga dengan pendengar yang baik.Peserta didik sering bercerita mengenai kehidupannya ketika di rumah.Sebagai guru harus solutif terhadap permasalahan yang dihadapi peserta didik.

4. Mengajak berkunjung ke rumah warga yang terkena musibah

Setiap manusia tentunya tidak ingin terkena musibah. Tetapi manusia tidak bisa melawan takdir, jika harus ditakdirkan dalam hidupnya terkena musibah tentunya hal itu akan terjadi juga. Begitulah pernyataan yang sering disebut oleh guru-guru di MI Muhammadiyah. Peserta didik akan diajak berkunjung ke rumah warga yang terkena musibah agar merasakan apa yang dirasakan oleh warga tersebut. Harapannya agar peserta didik akan selalu taat kepada Allah SWT meskipun dalam keadaan susah. Karena setiap musibah pasti ada hikmah dibaliknya.Terkadang pada saat warga ada yang terkena musibah, tidak lama setelah itu ada hikmah yang begitu nyata dan cepat terjadi. Sehingga membuat guru semakin mudah meyakinkan peserta didik untuk selalu bersabar ketika ada musibah yang menimpa.

5. Melakukan pengawasan

Dalam melakukan pengawasan bukan hanya guru saja di sekolahan, tetapi juga orang tua peserta didik harus mengawasi anak ketika di rumah dan tempat bermain.Karena sering terjadi bahwa ketika di sekolahan ada anak yang sangat baik sekali ketika di sekolahan tetapi ketika di rumah melakukan hal yang tidak baik dan tidak ada aturan.

\section{SIMPULAN}

Kesimpulan penelitian ini adalah guru harus menjadi teladan untuk melakukan hal yang baik, selain itu memberikan perhatian kepada semua 
peserta didik tanpa membandingkan dengan peserta didik lain. Komunikasi dengan baik juga sangat mempengaruhi sikap peserta didik.Mengajak berkunjung ke rumah warga yang terkena musibah, melakukan pengawasan yang dilakukan oleh guru dan orang tua agar segala aktivitas peserta didik dapat dilihat.Jadi peneliti menemukan hipotesis dalam penelitian yaitu dengan menjadi teladan, memberikan perhatian, berkomunikasi dengan baik kepada peserta didik, mengajak berkunjung ke rumah yang terkena musibah, melakukan pengawasn dapat mengembangkan kompetensi peserta didik.

\section{DAFTAR PUSTAKA}

Asmarawati, E., Riyadi, \& Sujadi, I. (2016). Proses integrasi sikap sosial dan spiritual dalam pembelajaran matematika pada siswa kelas VII SMP Negeri di kecamatan Purwodadi. Jurnal Elektronik Pembelajaran Matematika, 4(1), 5869.

Busyaeri, A., \& Muharom, M. (2016). Pengaruh Sikap Guru Terhadap Pengembangan Karakter (Peduli Sosial) Siswa Di Mi Madinatunnajah Kota Cirebon. Al Ibtida: Jurnal Pendidikan Guru MI, 2(1), 1-17. https://doi.org/10.24235/al.ibtida.snj. v2i1.177

Fauzan. (2017). Kurikulum dan Pembelajaran (Ke-1). Gaung Persada (GP) Press.

Fery, E., \& Saputro, H. (2019). 1 , 2 1,2. $7(2), 1-11$.

Ihwana, E., Juarsa, O., \& Agusdianita, N. (2017). Studi Deskriptif Pengelolaan Pembelajaran Tematik Dalam Mengembangkan Sikap Spiritual Di Kelas Iii B Sd N 09 Kota Bengkulu. Jurnal PGSD, 10(1), 51-60. https://doi.org/10.33369/pgsd.10.1.5 $1-60$

Mawarsih, S. E., Susilaningsih, \& Hamidi, N. (2013). Pengaruh Perhatian Orang Tua dan Motivasi Belajar Terhadap Prestasi Belajar Siswa SMA Negeri Jumapolo. Jupe Uns, 1(3), 1-13.

Nisa Program Studi Bimbingan Konseling, A. (2015). Pengaruh Perhatian Orang Tua Dan Minat Belajar Siswa Terhadap Prestasi Belajar Ilmu Pengetahuan Sosial. Faktor Jurnal Ilmiah Kependidikan, II(1), 1-9.

Suandi, N. (2014). Implementasi pengintegrasian sikap spiritual dan sosial dalam pembelajaran bahasa indonesia berbasis kurikulum 2013 di kelas VII SMP I Negri Singaraja. $3(1)$. 
Sugiyono. (2020). Metode Penelitian

Kualitatif (Ke-3). Alfabeta.

Triyanto. (2017). Desain Pengembangan

Kurikulum 2013 di Madrasah (Ke-

1). Kencana.

Wiguna, A. (2017). Upaya Mengembangkan Sikap Spiritual

Dan Sosial Peserta Didik Berbasis

Psikologi Positif Di Sekolah. $A L$ ASASIYYA: Journal Of Basic

Education, $\quad 1(2), \quad 47-61$.

https://doi.org/10.24269/ajbe.v1i2.68

4

64| J P D, p - I S S N : 2252 - 8156 , e - I S S N : 2579 - 3993 